\title{
The Pathogenesis of Alcohol-Induced Airflow Limitation in Acetaldehyde Dehydrogenase 2-Deficient Mice
}

\author{
Terufumi Shimoda $^{a}$ Yasushi Obase $^{b}$ Hiroto Matsuse $^{c}$ Sadahiro Asai $^{d}$ \\ Tomoaki Iwanaga $^{a}$

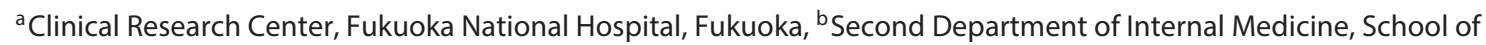 \\ Medicine, Nagasaki University, Nagasaki, ' Department of Respiratory Medicine, Oohashi Hospital, Toho University \\ Medical Center, Tokyo, and d SanRemo Rehabilitation Hospital, Sasebo, Japan
}

\section{Keywords}

Acetaldehyde $\cdot$ Alcohol-induced asthma $\cdot$ ALDH2-deficient mice $\cdot$ Ethanol $\cdot$ Histamine

\begin{abstract}
Background: In Japanese patients, alcohol-induced asthma is attributed to elevated plasma concentrations of acetaldehyde following alcohol consumption because of an acetaldehyde dehydrogenase 2 gene $(A L D H 2)$ polymorphism. The resulting increase in plasma histamine concentrations seems to trigger the onset of asthma symptoms. However, the specific pathogenic mechanism underlying this response remains unclear. ALDH2-deficient mice were therefore generated to investigate the pathogenesis of alcohol-induced asthma. Methods: ALDH2-deficient mice were generated using embryonic stem cells that were derived from C57BL/6 mice. The resulting mice were backcrossed into the BALB/c mice background. Exon 1 of $A L D H 2$ was replaced with the Neo cassette. Pure ethanol was orally administered to ALDH2-deficient and wild-type mice, and the plasma concentrations of ethanol, acetaldehyde, and histamine, in addition to enhanced pause (Penh) values, were determined and compared between the 2 groups. Results: We established an ALDH2-deficient mouse line to compare responses between wild-type and ALDH2-
\end{abstract}

deficient mice receiving orally administered ethanol. The results showed that the plasma concentrations of acetaldehyde $(p<0.0001)$ and histamine $(p<0.005)$ were significantly higher, and the Penh values $(p<0.01)$ were significantly greater in the ALDH2-deficient mice, although plasma ethanol levels were not different. Conclusions: We studied the pathogenesis of alcohol-induced asthma using ALDH2-deficient mice. The results demonstrated that alcohol intake resulted in an increase in acetaldehyde levels, and a subsequent increase in histamine levels, which induced airway constriction. Alcohol consumption is known to be an important factor that exacerbates bronchial asthma, and studies investigating this factor are useful for the treatment of patients with alcohol-induced asthma. @ 2017 S. Karger AG, Basel

\section{Introduction}

Approximately half of Japanese asthma patients have experienced an exacerbation of the symptoms of asthma after drinking alcohol. This condition is referred to as alcohol-induced asthma [1]. Consumed ethanol is metabolized to acetaldehyde in the liver, and acetaldehyde is then further converted to nontoxic acetic acid by acetaldehyde

\section{KARGER}

(c) 2017 S. Karger AG, Basel

E-Mail karger@karger.com

www.karger.com/iaa
Correspondence to: Dr. Terufumi Shimoda

Clinical Research Center, Fukuoka National Hospital

4-39-1 Yakatabaru, Minami-ku

Fukuoka 811-1394 (Japan)

E-Mail t-shimoda@mfukuoka2.hosp.go.jp 
Fig. 1. Targeting strategy and PCR genotyping of ES cell DNA. a The ALDH2 exon 1 was replaced with a Neo cassette using homologous recombination. In the targeting construct, a $2.4-\mathrm{kb} 5^{\prime}$ fragment and a $7.8-\mathrm{kb}$ $3^{\prime}$ fragment were used as the short and long homologous arms, respectively. Arrows indicate the primers that were used for $5^{\prime}$ homologous recombination ( $\mathrm{f} 1, \mathrm{r} 1)$. b PCR was performed using the Neo cassette-specific primers $\mathrm{r} 1$ and $\mathrm{f} 1$, which corresponded to the short arm (producing a $3.0-\mathrm{kb}$ fragment from the knockout [KO] allele). f1 primer: $5^{\prime}$-CCTAAGAATGTCTCAGACCAGCTAT- $3^{\prime}$; r1 primer: $5^{\prime}$-CTTCCTCGTGCTTTACGGTATC-3'.

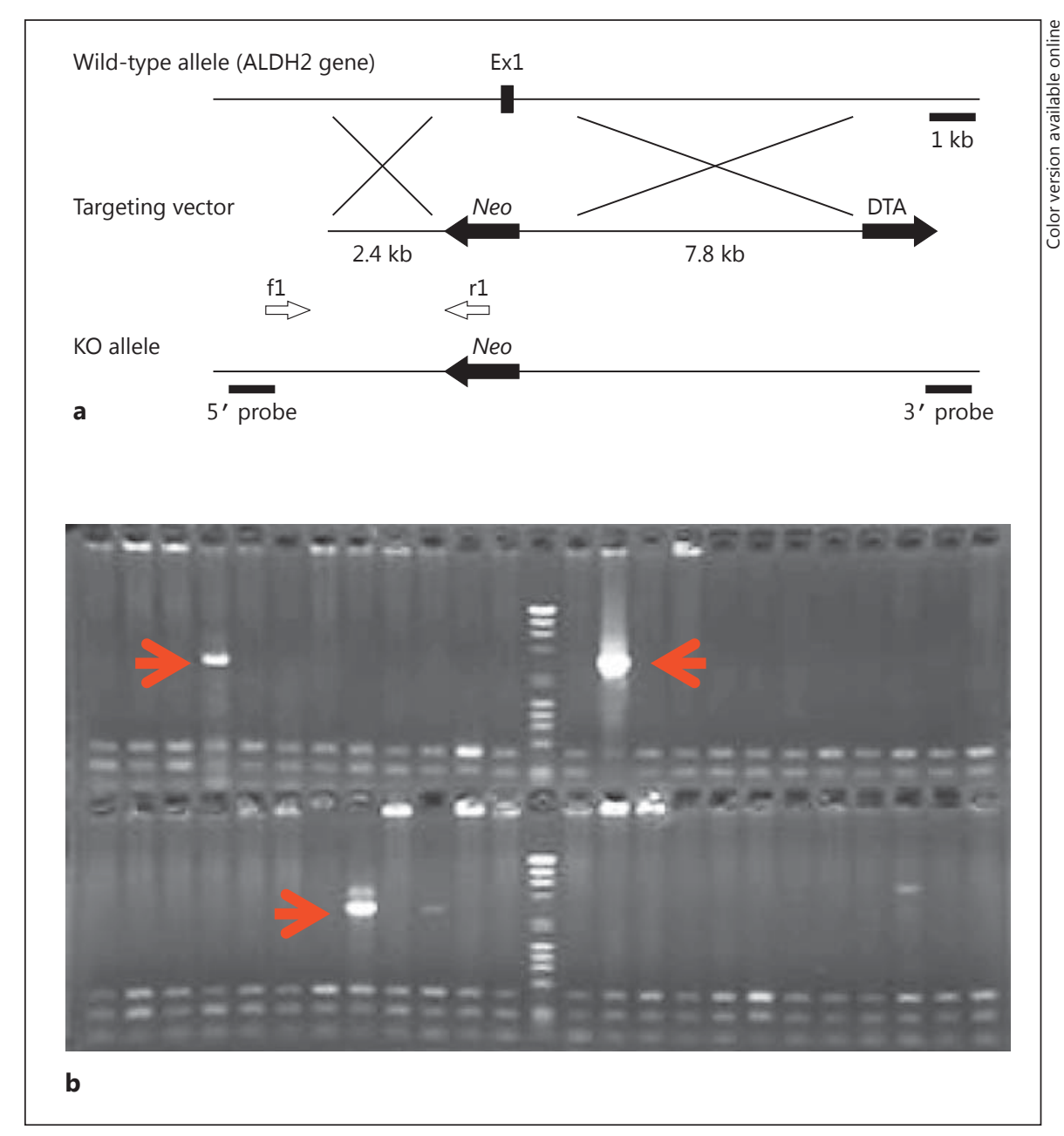

dehydrogenase 2 (ALDH2) $[2,3]$. ALDH2 is a member of the ALDH superfamily, which comprises 9 major families. ALDH2 is localized in the mitochondria and plays a role in the $\mathrm{NAD}^{+}$-dependent irreversible oxidation of a wide range of aliphatic and aromatic aldehydes into carboxylates [3]. Previous human studies have demonstrated that there is a correlation between the $A L D H 2$ gene polymorphism and alcohol-induced asthma $[4,5]$. Polymorphism-dependent abnormal ALDH2 activity is thought to induce airway constriction in alcohol-induced asthma by elevating the plasma levels of acetaldehyde following the consumption of alcohol. Impaired ALDH2 activity leads to high peak levels of acetaldehyde and to histamine release $[1,4,6]$. Ethanol itself has been reported to cause bronchodilation and suppress airway hyperresponsiveness $[7,8]$, and inhaling acetaldehyde has been shown to stimulate airway hyperresponsiveness in asthma patients [9]. Furthermore, Myou et al. [10, 11] have reported that acetaldehyde inhalation induces histamine- mediated airway constriction in humans and guinea pigs. This effect was also observed in a study in which acetaldehyde was intravenously injected [12]. However, the molecular mechanisms underlying alcohol-induced asthma are not fully understood. In vivo experimental studies using animal models of a variety of diseases have been useful for exploring the mechanisms underlying many biological processes. In this study, we generated ALDH2deficient mice and assessed whether they exhibited a phenotype resembling alcohol-induced asthma including elevated plasma acetaldehyde and histamine levels, following ethanol consumption.

\section{Material and Methods}

Generation of ALDH2-Deficient Mice

In the mouse genome, the gene $A L D H 2$ consists of 13 exons and 12 introns and has a full length of approximately $26 \mathrm{~kb}$ [13]. A targeting vector was created by replacing a $2.1-\mathrm{kb}$ region con- 
Fig. 2. Southern blot analysis of genomic DNA obtained following the homologous recombination of ES cells. Genomic DNA obtained from ES cells after homologous recombination was digested with HindIII (or NdeI) and then hybridized with the external $5^{\prime}$ probe or $3^{\prime}$ probe. The $5^{\prime}$ probe detected a 4.2-kb wild-type (WT) band and a $5.4-\mathrm{kb}$ knockout $(\mathrm{KO})$ band in the $\mathrm{KO}$ allele. The $3^{\prime}$ probe detected an $11.3-\mathrm{kb}$ WT band and a 10.9-kb KO band in the $\mathrm{KO}$ allele.

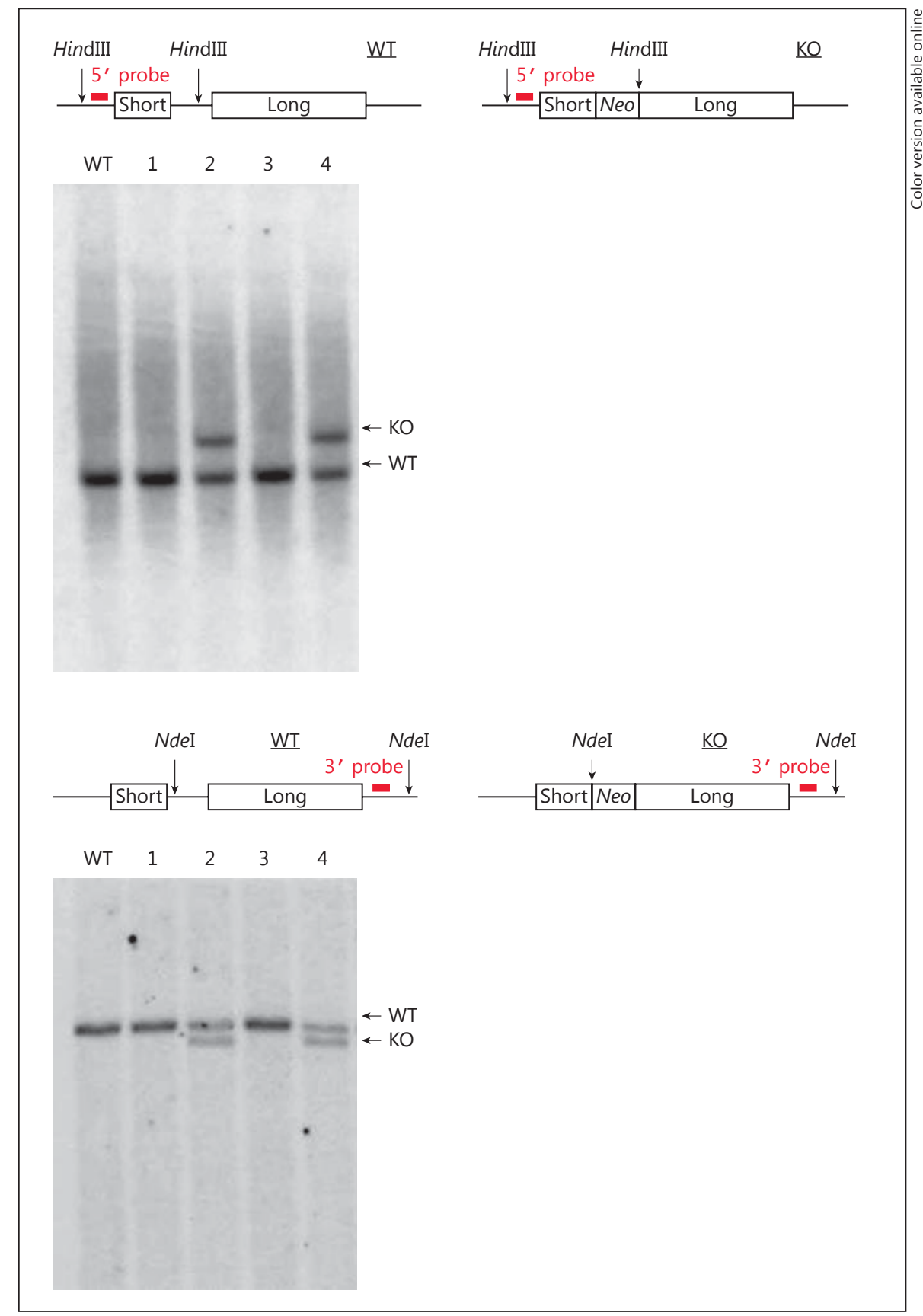

taining the first exon, which includes the initiation codon of $A L D H 2$, and a Neo cassette (Fig. 1a). This vector was linearized and transfected into C57BL/6 embryonic stem (ES) cells via electroporation, and the G418-resistant cell clones were isolated. To confirm the homologous recombination of the target gene in the transfected ES cells, genomic DNA was extracted from the isolated cells, and analyzed using PCR with primers that were homologous to specific sequences within the region of homologous recombination. A 3.0-kb band was detected in some clones (Fig. 1b). To further confirm these results, genomic DNA was extracted from the
ES cells, digested using restriction enzymes, and analyzed using Southern blot analysis with probes that were homologous to specific sequences within the region of homologous recombination. Genomic DNA was digested using either HindIII or NdeI and then hybridized with 2 probes, a $5^{\prime}$ probe and a $3^{\prime}$ probe, that were specific to the $5^{\prime}$ and $3^{\prime}$ ends, respectively, of the region of homologous recombination. The $5^{\prime}$ probe detected a $4.2-\mathrm{kb}$ band in the wildtype allele and a $5.4-\mathrm{kb}$ band in the knockout allele. The $3^{\prime}$ probe detected an 11.3-kb band in the wild-type allele and a 10.9-kb band in the knockout allele (Fig. 2). In addition, the HindIII-digested 
Fig. 3. The clones in lanes 2 and 4 possess a Neo resistance gene-containing DNA fragment that inserted into the intended genomic region. The clones in lanes 1 and 3 possess a $\mathrm{Neo}$ resistance gene-containing DNA fragment that inserted into a site located outside the intended genomic region (all of the clones in lanes 1-4 are Neo-resistant clones). Neo-R, Neo cassette-specific primer; KO, knockout; WT, wild type.

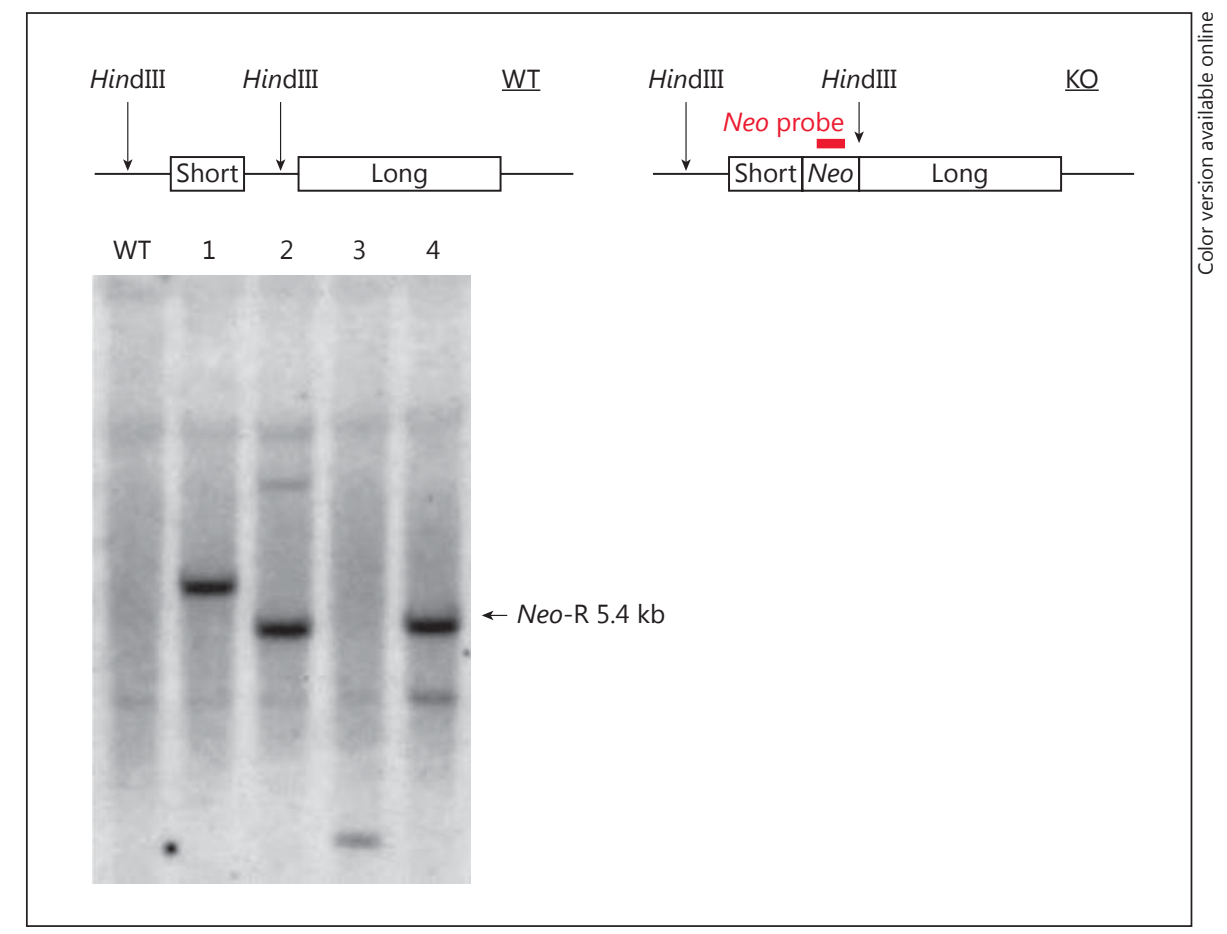

genomic DNA was hybridized using a probe that was specific to the Neo resistance gene within the region of homologous recombination. A 5.4-kb band was also detected in some clones (Fig. 3). These results indicate that homologous recombination occurred as intended, and resulted in ES cells that contained the correct insertion sequence in the appropriate target region of the gene. ES cells that were found to have undergone homologous recombination were injected into $\mathrm{BALB} / \mathrm{c}$ mouse blastocysts to generate chimeric (F0) mice, which were identified by their coat color. The F0 male mice were crossed with $\mathrm{C} 57 \mathrm{BL} / 6 \mathrm{~J}$ female mice to produce $\mathrm{F} 1$ transgenic $\left(A L D H 2^{+/-}\right)$mice. The genotypes of the mice were confirmed based on the detection of a $3.0-\mathrm{kb}$ band on PCR using the same primer set that was used for the PCR analysis of the transfected ES cells (Fig. 4a). Next, male and female $A L D H 2^{+/-}$mice were crossed to establish ALDH2-deficient $\left(A L D H 2^{-/-}\right)$mice. The genotypes of these mice were confirmed using PCR with primers that were homologous to specific sequences within the region of homologous recombination. The results revealed a single $2.2-\mathrm{kb}$ band for $A L D H 2^{+/+}$mice, both a $2.2-\mathrm{kb}$ and an approximately 650-bp band for $A L D H 2^{+/-}$mice, or a single band of approximately $650 \mathrm{bp}$ for $A L D H 2^{-/-}$mice (Fig. 4b). ALDH2-deficient mice were maintained by mating the same ALDH2-deficient mice amongst each other. These mice were used to monitor plasma ethanol and acetaldehyde concentrations and to measure enhanced pause (Penh) values, as described below.

Furthermore, to achieve a genetic background that was closer to that of $\mathrm{BALB} / \mathrm{c}$ mice, in which allergic reactions are easier to induce [14], ALDH2-deficient male mice were crossed with BALB/ cCrSlc female mice (Japan SLC, Inc.), and the resulting ALDH2 $2^{+/-}$ male and female progeny were then crossed with each other. The resulting ALDH2-deficient mice were used to monitor plasma histamine concentrations, as described below.

Alcohol-Induced Airflow Limitation in ALDH2-Deficient Mice
All experiments performed were conducted with the prior approval of the Animal Experiment Committee at UNITECH Co., Ltd. (approval No. AGR SHI-140901K-AS).

\section{Blood Biochemistry Tests}

Plasma ethanol and acetaldehyde concentrations were monitored in wild-type female mice (aged 8-10 weeks, C57BL/6JJcl; CLEA Japan, Inc.) and ALDH2-deficient female mice (aged 10-18 weeks). The mice were administered an intraperitoneal dose of $0.5 \%$ carboxymethyl cellulose that was followed $1 \mathrm{~h}$ later by a 10 $\mathrm{mL} / \mathrm{kg}$ dose of $25 \%$ ethanol. The doses were administered via gavage. Some of the mice were anesthetized via an intraperitoneal injection with $10 \%$ Somnopentyl (pentobarbital sodium) so that their entire blood volume could be collected from the heart using heparinized needles. This procedure was performed either before dosing or at 1 or $2 \mathrm{~h}$ after dosing. The collected blood was centrifuged at $10,000 \mathrm{rpm}$ for $5 \mathrm{~min}$ at $4^{\circ} \mathrm{C}$ to obtain plasma samples. To determine plasma ethanol concentrations, $50 \mu \mathrm{L}$ of plasma was mixed with $400 \mu \mathrm{L}$ of ice-cold $0.33 \mathrm{~mol} / \mathrm{L}$ perchloric acid, and the solution was centrifuged at $3,000 \mathrm{rpm}$ for $10 \mathrm{~min}$ at $4^{\circ} \mathrm{C}$. The supernatant was assayed using an ethanol test kit (F-kit Ethanol; J.K. International Inc., 176290). To determine plasma acetaldehyde concentrations, plasma samples were mixed with an equal amount of ice-cold $1.0 \mathrm{~mol} / \mathrm{L}$ perchloric acid, and the solution was centrifuged at 3,000 $\mathrm{rpm}$ for $10 \mathrm{~min}$ at $4^{\circ} \mathrm{C}$. The supernatant was then collected and neutralized to a $\mathrm{pH}$ of approximately 7 using 1.0 $\mathrm{mol} / \mathrm{L}$ potassium hydroxide, and this solution was centrifuged at $3,000 \mathrm{rpm}$ for $10 \mathrm{~min}$ at $4^{\circ} \mathrm{C}$. The supernatant was then assayed using an acetaldehyde test kit (F-kit Acetaldehyde; J.K. International Inc., 668613).

Plasma histamine concentrations were monitored in wild-type female mice (aged 10-18 weeks, BALB/cCrSlc, Japan SLC, Inc.) 
Fig. 4. Generation of ALDH2-knockout (KO) mice. a PCR genotyping of tail DNA extracted from F1 heterozygous mice. The primer was the same as that used in the PCR genotyping of ES cells. b PCR genotyping of tail DNA extracted from F2 heterozygous mice utilizing the Neo cassettespecific primer Neo-R (5'-CTTCCTCGTGCTTTACGGTATC- $3^{\prime}$ ) for the mutant allele (658 bp) as well as a genomic $5^{\prime}$ primer (WT-R: $5^{\prime}$-TACTTCACAACCACGTTCTTTCAT $-3^{\prime}$ ) and the same $3^{\prime}$ primer (WT-F: 5'-TGTAGTCAATGAGACAGCAAGTAGC- $3^{\prime}$ ) to identify the wild-type (WT) allele (2,263 bp). MK, midkine.
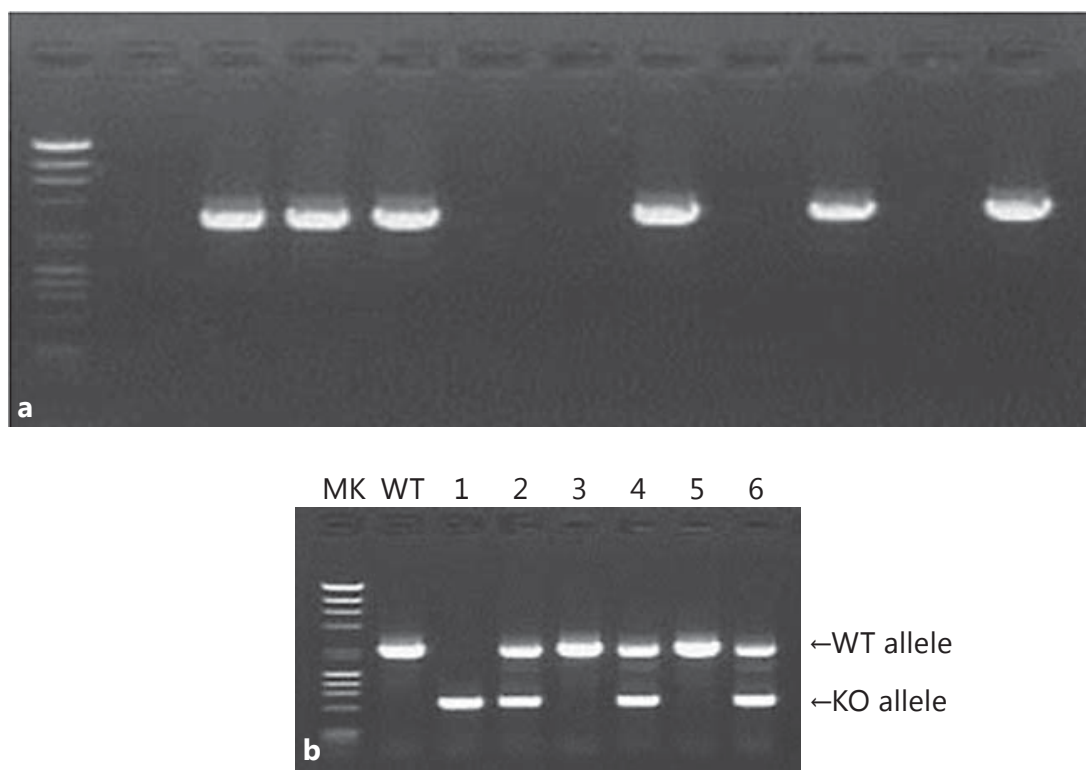

and 32-week-old ALDH2-deficient female mice. The mice were administered a $10 \mathrm{~mL} / \mathrm{kg}$ dose of $25 \%$ ethanol via gavage. Plasma histamine concentrations were determined before dosing and at $15,30,60$, and 120 min after dosing. Blood samples were drawn from the caudal vein of restrained mice without anesthesia using heparinized hematocrit capillary tubes (TGL Inc.). To determine plasma histamine concentrations, whole-blood samples were centrifuged at 15,000 rpm for $3 \mathrm{~min}$ at room temperature, and the isolated plasma was analyzed using a histamine test kit (Bertin Pharma).

\section{Penh Measurement}

Penh values were measured in wild-type male mice (C57BL/6J, 16 weeks old), NC/Nga mice (NC/NgaTndCrlj, 8-9 weeks old; Charles River Laboratories International, Inc.), and ALDH2-deficient mice (15 weeks old). The mice were administered a $10 \mathrm{~mL} /$ $\mathrm{kg}$ dose of $25 \%$ ethanol via gavage, and the Penh values were then analyzed using a respiratory function analyzer (BUXCO Japan, Inc.). The Penh analysis was performed at $1 \mathrm{~min}$ intervals for 10 min before dosing and at $1,2,3,4,5$, and $8 \mathrm{~h}$ after dosing. Penh values were calculated as the mean of the measurements taken 6-10 min before dosing (measurements taken after 1-5 min were not used).

\section{Statistical Analysis}

The data obtained from the blood biochemistry tests are expressed as the mean \pm standard deviation, and the data from the Penh analysis are reported as the mean \pm standard error. Biochemical data were analyzed using the Student $t$ tests or the Welch $t$ test, while the Penh data were analyzed using single-factor ANOVA and the Tukey-Kramer post hoc test. A $p$ value $<0.05$ was considered to indicate statistical significance. These statistical analyses were conducted using Statcel 3 (OMS Publishing, Saitama, Japan).

\section{Results}

\section{Plasma Ethanol and Acetaldehyde Concentrations after Oral Ethanol Challenge}

Plasma ethanol and acetaldehyde concentrations were monitored in wild-type and ALDH2-deficient mice following the oral administration of ethanol. There was no difference in plasma ethanol concentrations between the wild-type and ALDH2-deficient mice (Fig. 5a). Plasma acetaldehyde concentrations were significantly higher in the ALDH2-deficient mice than in the wild-type mice at $1 \mathrm{~h}$ post-dose $(0.0020 \pm 0.0004 \mathrm{~g} / \mathrm{L}$ in wild-type $[n=3]$ vs. $0.0086 \pm 0.0004 \mathrm{~g} / \mathrm{L}$ in ALDH2-deficient [ $n=3$ ],$p<0.001$, Student $t$ test $)$ and at $2 \mathrm{~h}$ post-dose $(0.0014 \pm 0.0001 \mathrm{~g} / \mathrm{L}$ in wild-type $[n=3]$ vs. $0.0088 \pm 0.0001 \mathrm{~g} / \mathrm{L}$ in ALDH2deficient $[n=3], p<0.05$, Welch $t$ test) (Fig. 5b). Predose plasma acetaldehyde concentrations were also significantly higher in ALDH2-deficient mice than in wildtype mice $(0.0017 \pm 0.0001 \mathrm{~g} / \mathrm{L}$ in wild-type $[\mathrm{n}=3]$ vs. $0.0026 \pm 0.0002 \mathrm{~g} / \mathrm{L}$ in ALDH2-deficient [ $=3], p<0.01$, Student $t$ test) (Fig. 5b).

\section{Plasma Histamine Concentrations after Oral Ethanol Challenge}

Plasma histamine concentrations were monitored in wild-type and ALDH2-deficient mice after oral ethanol administration. Plasma histamine concentrations were significantly higher in ALDH2-deficient mice than in 


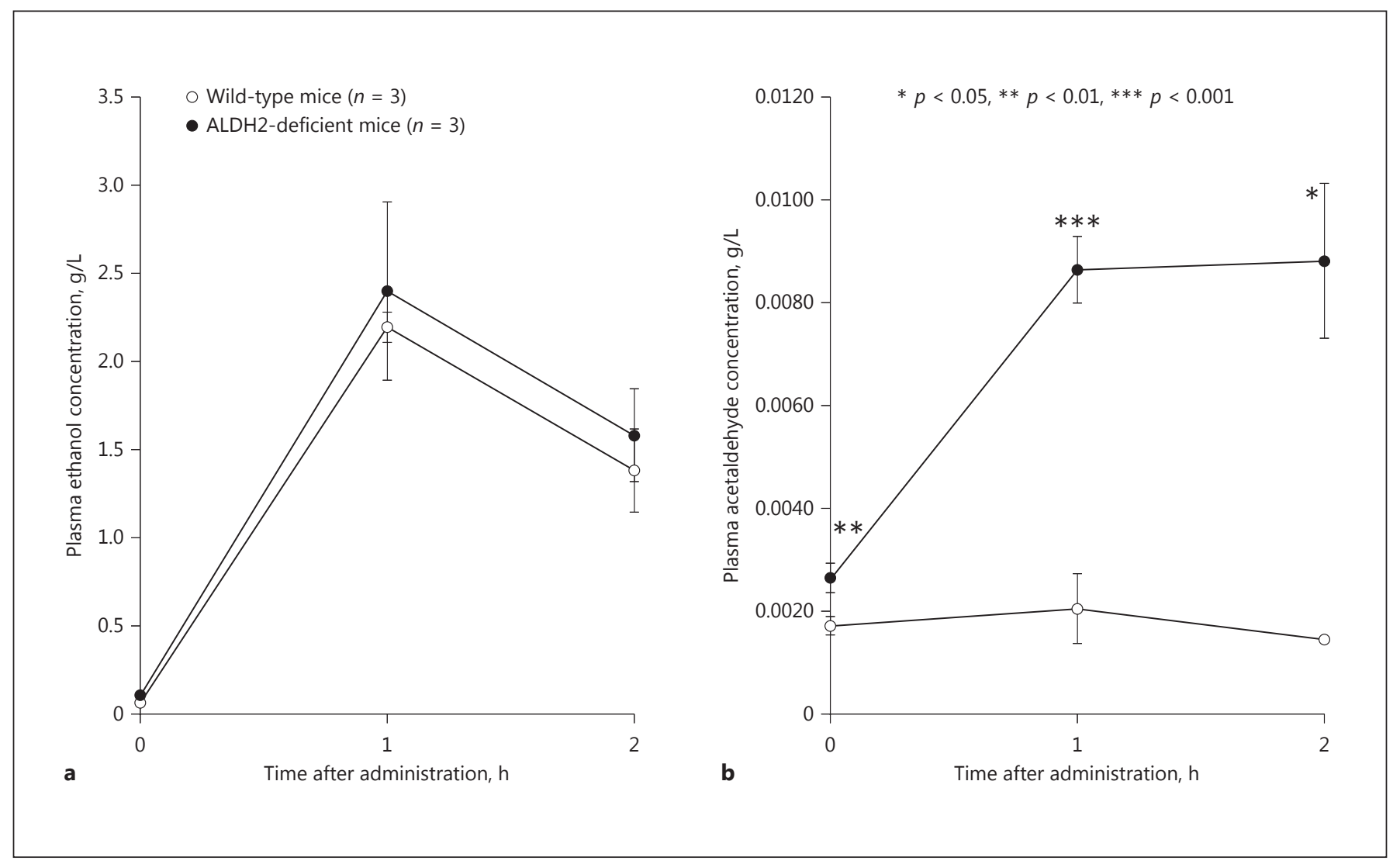

Fig. 5. Plasma ethanol (a) and plasma acetaldehyde (b) concentrations after oral ethanol challenge. Mean \pm SD.

wild-type mice at $15 \mathrm{~min}$ post-dose $(3,195 \pm 940 \mu \mathrm{M}$ in wild-type $[n=3$ ] vs. $12,158 \pm 3,869 \mu \mathrm{M}$ in ALDH2-deficient $[n=3], p<0.05$, Student $t$ test), 30 min post-dose $(3,380 \pm 2,533 \mu \mathrm{M}$ in wild-type $[n=3]$ vs. $17,092 \pm 2,862$ $\mu \mathrm{M}$ in ALDH2-deficient [ $n=3$ ], $p<0.005), 60$ min postdose $(2,509 \pm 1,200 \mu \mathrm{M}$ in wild-type $[n=3]$ vs. $15,552 \pm$ $1,639 \mu \mathrm{M}$ in ALDH2-deficient $[n=3] ; p<0.005)$, and 120 min post-dose $(3,329 \pm 806 \mu \mathrm{M}$ in wild-type $[n=3]$ vs. $12,025 \pm 4,971 \mu \mathrm{M}$ in ALDH2-deficient $[n=3], p<0.05$ ) (Fig. 6a).

\section{Penh Values after Oral Ethanol Challenge}

The Penh analysis was performed on wild-type and ALDH2-deficient mice after oral ethanol administration. Penh values were significantly higher in ALDH2deficient mice than in wild-type mice at $1 \mathrm{~h}$ post-dose $(0.4815 \pm 0.044$ in wild-type $[n=5]$ vs. $1.7615 \pm 0.3016$ in ALDH2-deficient $[n=5], p<0.01$, Tukey-Kramer post hoc test), $2 \mathrm{~h}$ post-dose $(0.4636 \pm 0.0782$ in wild-type vs. $1.179 \pm 0.2037$ in ALDH2-deficient, $p<0.01), 5$ h postdose $(0.5045 \pm 0.0255$ in wild-type vs. $0.6531 \pm 0.0149$ in
ALDH2-deficient; $p<0.05)$, and 8 h post-dose $(0.4443 \pm$ 0.0294 in wild-type vs. $0.7057 \pm 0.0726$ in ALDH2-deficient, $p<0.05$ ) (Fig. 6b). Next, ethanol was administered to nonimmunized $\mathrm{NC}$ mice to compare the extent of airway constriction between NC and ALDH2-deficient mice. Penh values were significantly higher in NC mice than in wild-type mice before ethanol was administered $(0.4582 \pm 0.0111$ in wild-type $[n=5]$ vs. $0.6980 \pm 0.0302$ in NC $[n=5], p<0.01$, Tukey-Kramer post hoc test), at $5 \mathrm{~h}$ post-dose $(0.5045 \pm 0.0255$ in wild-type vs. $0.8460 \pm$ 0.050 in NC, $p<0.01)$ and at $8 \mathrm{~h}$ post-dose $(0.4444 \pm$ 0.0294 in wild-type vs. $0.7821 \pm 0.0512$ in NC, $p<0.01)$. However, the phenotype was more prominent in the ALDH2-deficient mice before ethanol administration $(0.6980 \pm 0.0302$ in NC $[n=5]$ vs. $0.5496 \pm 0.0351$ in ALDH2-deficient [ $n=5], p<0.01$, Tukey-Kramer post hoc test), at $1 \mathrm{~h}$ post-dose $(0.8970 \pm 0.1917$ in NC vs. $1.7615 \pm 0.3016$ in ALDH2-deficient, $p<0.05)$ and at $5 \mathrm{~h}$ post-dose $(0.8460 \pm 0.050$ in $\mathrm{NC}$ vs. $0.6531 \pm 0.0149$ in ALDH2-deficient, $p<0.01$ ) (Fig. 6b). 


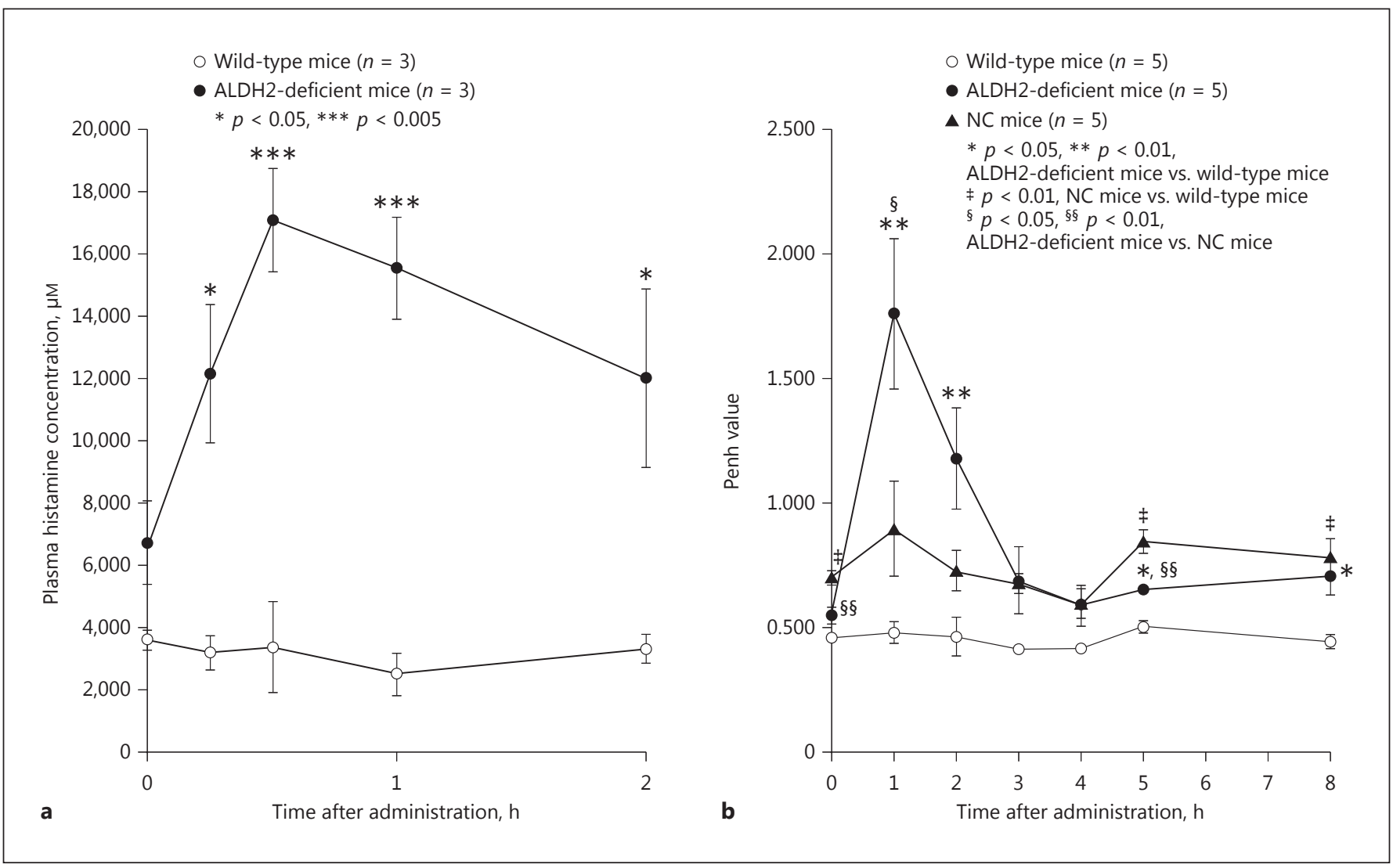

Fig. 6. Plasma histamine concentrations (a) and Penh values (b) after oral ethanol challenge. Mean \pm SD.

\section{Discussion}

ALDH2 is the primary enzyme that converts acetaldehyde into acetic acid during alcohol metabolism $[2,3]$. To examine whether the ALDH2-deficient mice generated in this study exhibited metabolic aberrations in the conversion of acetaldehyde to acetic acid, we monitored plasma ethanol and acetaldehyde concentrations in wild-type and ALDH2-deficient mice after oral ethanol administration. There was no difference in plasma alcohol concentrations between the wild-type and ALDH2-deficient mice, but plasma acetaldehyde concentrations were significantly higher in the ALDH2-deficient mice than in the wild-type mice. These results indicate that ALDH2 plays a major role in the conversion of acetaldehyde during the process of the metabolic breakdown of orally administered ethanol, and that this process is impaired in ALDH2-deficient mice. In addition, pre-dose plasma acetaldehyde concentrations were significantly higher in ALDH2-deficient mice than in wild-type mice. This suggests that while acetaldehyde metabolism is not related to ethanol consumption, it was also defective in our ALDH2-deficient mice. Based on our previous studies, abnormal ALDH2 activity induces airway constriction following alcohol consumption by increasing plasma acetaldehyde levels, which causes the subsequent release of histamine from mast cells or basophils $[1,4]$. Next, to verify that ALDH2-deficient mice demonstrate a phenotype similar to the one we previously reported, we monitored plasma histamine concentrations and Penh values after the oral administration of ethanol in wild-type and ALDH2-deficient mice. The ALDH2-deficient mice demonstrated significantly higher plasma histamine concentrations and Penh values than the wild-type mice. These results indicate that excess histamine release occurs as a result of the increase in plasma acetaldehyde concentrations that was observed in the ALDH2 mice. NC/Nga (NC) mice, which are often used as an animal model for naturally occurring dermatitis, have been shown to develop asthma-like symptoms as a result of ovalbumin immunization [15]. When we orally administered ethanol to nonimmunized NC mice to compare the extent of airway 
constriction between NC and ALDH2-deficient mice, we found that the Penh values were significantly higher in the NC mice than in the wild-type mice. This indicates that even more severe airway obstruction was induced in ALDH2-deficient mice than in NC mice. Additionally, these results indicate that both allergic response pathways and ALDH2 deficiency play an important role in the pathogenesis of alcohol-induced asthma. Previous studies in humans and in vitro systems have demonstrated that drinking alcohol causes acetaldehyde levels to increase, which leads to an increase in the release of histamine from mast cells or basophils, and the consequential induction of airway constriction $[1,16]$. Studies have also indicated that administering antihistamines could prevent alcohol-induced asthma in humans $[17,18]$. These findings suggest that excess histamine release plays an important role in alcohol-induced asthma. Further studies are required to explore the mechanisms underlying this process, including how histamine localizes to target organs, the molecular mechanism associated with the actions of histamine, the roles of the nonhistamine chemical mediators that are released from mast cells and basophils, and the characteristics of the immune system response in these patients $[19,20]$. Future potential research topics include the study of sensitized ALDH2-deficient mice and an assessment of the inhibitory effects caused by various agents.

In summary, in Japanese patients, alcohol-induced asthma is thought to be triggered by an increase in plasma acetaldehyde concentration following the consumption of alcohol. This increase is triggered because of abnormal ALDH2 activity that results from a gene polymorphism $[4,5]$. We produced ALDH2-deficient mice that showed elevated plasma acetaldehyde levels and increased airway obstruction after they were administered an oral dose of ethanol, and we demonstrated that symptoms resembling alcohol-induced asthma were easily induced in this mouse model system. The ALDH2-deficient mouse system established in this study is therefore expected to substantially contribute to future progress in in vivo research studies of alcohol-induced asthma.

\section{Acknowledgements}

The authors would like to thank Mr. Masahiko Satoh, who is an original researcher at UNITECH Co., Ltd., Chiba, Japan, for his technical assistance.

\section{Funding Sources}

This study was supported by research funding provided by Fukuoka National Hospital.

\section{Disclosure Statement}

The authors have declared that they have no conflict of interest.

\section{References}

1 Shimoda T, Kohno S, Takao A, Fujiwara C, Matsuse H, Sakai H, Watanabe T, Hara K, Asai S: Investigation of the mechanism of alcohol-induced bronchial asthma. J Allergy Clin Immunol 1996;97:74-84.

2 Crabb DW, Matsumoto M, Chang D, You M: Overview of the role of alcohol dehydrogenase and aldehyde dehydrogenase and their variants in the genesis of alcohol-related pathology. Proc Nutr Soc 2004;63:49-63.

3 Gemma S, Vichi S, Testai E: Individual susceptibility and alcohol effects: biochemical and genetic aspects. Ann Ist Super Sanita 2006;42:8-16.

4 Takao A, Shimoda T, Kohno S, Asai S, Harda S: Correlation between alcohol-induced asthma and acetaldehyde dehydrogenase- 2 genotype. J Allergy Clin Immunol 1998;101:576580 .
5 Matsuse H, Shimoda T, Fukushima C, Mitsuta K, Kawano T, Tomari S, Saeki S, Kondoh Y, Machida I, Obase Y, Asai S, Kohno S: Screening for acetaldehyde dehydrogenase 2 genotype in alcohol-induced asthma by using the ethanol patch test. J Allergy Clin Immunol 2001;108:715-719.

6 Linneberg A, Gonzalez-Quintela A, Vidal C, Jørgensen T, Fenger M, Hansen T, Pedersen O, Husemoen LL: Genetic determinants of both ethanol and acetaldehyde metabolism influence alcohol hypersensitivity and drinking behaviour among Scandinavians. Clin Exp Allergy 2010;40:123-130.

7 Myou S, Fujimura M, Nishi K, Watanabe K, Matsuda M, Ohka T, Matsuda T: Effect of ethanol on airway caliber and nonspecific bronchial responsiveness in patients with alcoholinduced asthma. Allergy 1996;51:52-55.
8 Oldenburg PJ, Poole JA, Sisson JH: Alcohol reduces airway hyperresponsiveness (AHR) and allergic airway inflammation in mice. Am J Physiol Lung Cell Mol Physiol 2012; 302:L308-L315.

9 Myou S, Fujimura M, Nishi K, Matsuda M, Ohka T, Matsuda T: Potentiating effect of inhaled acetaldehyde on bronchial responsiveness to methacholine in asthmatic subjects. Thorax 1994;49:644-648.

10 Myou S, Fujimura M, Nishi K, Ohka T, Matsuda T: Aerosolized acetaldehyde induces histamine-mediated bronchoconstriction in asthmatics. Am Rev Respir Dis 1993;148:940-943.

11 Myou S, Fujimura M, Bando T, Saito M, Matsuda T: Aerosolized acetaldehyde, but not ethanol, induces histamine-mediated bronchoconstriction in guinea pigs. Clin Exp Allergy 1994;24:140-143. 
12 Myou S, Fujimura M, Saito M, Matsuda T: Intravenous injection of acetaldehyde but not ethanol induces histamine-mediated bronchoconstriction in guinea pigs. Respiration 1995;62:143-147.

13 Chang C, Yoshida A: Cloning and characterization of the gene encoding mouse mitochondrial aldehyde dehydrogenase. Gene 1994;148:331-336.

14 Gueders MM, Paulissen G, Crahay C, Quesada-Calvo F, Hacha J, Van Hove C, Tournoy K, Louis R, Foidart JM, Noël A, Cataldo DD: Mouse models of asthma: a comparison between $\mathrm{C} 57 \mathrm{BL} / 6$ and $\mathrm{BALB} / \mathrm{c}$ strains regarding bronchial responsiveness, inflammation, and cytokine production. Inflamm Res 2009;58: 845-854.
15 Iwasaki T, Tanaka A, Itakura A, Yamashita N, Ohta K, Matsuda H, Onuma M: Atopic NC/ Nga mice as a model for allergic asthma: severe allergic responses by single intranasal challenge with protein antigen. J Vet Med Sci 2001;63:413-419.

16 Kawano T, Matsuse H, Kondo Y, Machida I, Saeki S, Tomari S, Mitsuta K, Obase Y, Fukushima C, Shimoda T, Kohno S: Acetaldehyde induces histamine release from human airway mast cells to cause bronchoconstriction. Int Arch Allergy Immunol 2004;134:233-239.

17 Takao A, Shimoda T, Matsuse H, Mitsuta K, Obase Y, Asai S, Kohno S: Inhibitory effects of azelastine hydrochloride in alcohol-induced asthma. Ann Allergy Asthma Immunol 1999;82:390-394.

18 Myou S, Fujimura M, Nishi K, Ohka T, Matsuda T: Inhibitory effect of terfenadine, a selective $\mathrm{H} 1$ histamine antagonist, on alcoholic beverage-induced bronchoconstriction in asthmatic patients. Eur Respir J 1995;8: 619-623.
19 Linneberg A, Friedrich N, Husemoen LL, Thuesen B, Gonzalez-Quintela A, Vidal C, Bodtger U, Johansen N, Drivsholm T: Incidence and remission of specific IgE aeroallergen sensitization from age of 40 to 60 years, and association with alcohol consumption. Int Arch Allergy Immunol 2010;151:142-148.

20 Linneberg A, Fenger RV, Husemoen LL, Thuesen BH, Skaaby T, Gonzalez-Quintela A, Vidal C, Carlsen BC, Johansen JD, Menné T, Stender S, Melgaard M, Szecsi PB, Berg ND, Thyssen JP: Association between loss-offunction mutations in the filaggrin gene and self-reported food allergy and alcohol sensitivity. Int Arch Allergy Immunol 2013;161: 234-242. 